\title{
sobre Años de aprendizaje. Subjetividad adolescente, literatura y formación en la Argentina de los años sesenta, de Paola Piacenza.
}

\author{
Buenos Aires: Miño y Dávila, 2017 \\ SERGIO PERALTA Universidad Nacional del Litoral - CONICET, Argentina / sergio.dl.peralta@gmail.com
}

\section{Cada veinticinco}

Un chiste común entre historiadores es decir que cada veinticinco Guinzburgs (microhistoriadores) habrá un Halperín Donghi (totalizador). Es la ley primera de la división entre trabajo de archivo e investigación bibliográfica. Paola Piacenza hace las veces de Halperín para contar los años sesenta largos desde otro lado («reordenar las series»): el aporte -insoslayable para el tesista en apuros por su calidad metodológica - está más en el cuentito' que permite articular gran cantidad de literaturas que en la lectura de cada texto literario en particular. O, para decir mejor, la lectura de cada texto literario está supeditada al cuentito que hace corpus y otorga valor: lleva agua para su molino drenando esos textos, rehidratando esa tierra tan visitada como son los años sesenta, sobre todo en sus especulares noventa (la Edad de Oro) ${ }^{2}$ y hoy por hoy, como relato de Estado (o farsa): «estoy aquí para ayudarlos a crecer» insiste Macri. En efecto, la autora emparenta su investigación con debates de fines de los noventa en la crítica literaria argentina. Es una clave de lectura abordar el libro como deriva de los seminarios de posgrado sobre novela gótica y novela de aprendizaje que José Amícola comenzó a dictar en 1996 en la Universidad de La Plata, cuya importancia entrevemos por huellas de los seminarios en trabajos de José Luis de Diego y Carolina Cuesta. En tal sentido, hay un después de la investigación de Piacenza, porque cierra parte de ese ciclo aunque cambiando la unidad de análisis: de novela a narrema con decisiones polémicas: referirse a «escritura femenina» o escoger la partida de María Teresa Gramuglio frente a la ahora desmedida afirmación de Amícola acerca de la inexistencia de novela de aprendizaje rioplatense, por dar sólo dos ejemplos.

Ese cuentito fruto del guessing es el «relato de formación» con el que Piacenza recorre transversalmente los niveles macro (discurso político), meso (discurso pedagógico y divulgación científica) y micro (discurso literario o conjetural) de una zona del discurso social que recorta como época. Prepara su caja de herramientas con toques de historia conceptual. Luego lee sintomáticamente (síntoma: lo que cae junto): busca huellas (deduciendo) e indicios (induciendo) de una época en textos literarios con personaje, punto de vista o forma adolescente y en producción teórica

\footnotetext{
Para citar este artículo: Peralta, Sergio (2018). «Sobre: Años de aprendizaje. Subjetividad adolescente, literatura y formación en la Argentina de los años sesenta, de Paola Piacenza». El taco en la brea 7 (diciembre-mayo), 221-224 Santa Fe, Argentina: UNL. DOI: https://doi.org/10.14409/tb.voi7.7369
} 
sobre adolescencia, utilizando el quiasmo como descripción y como «prueba» de sus abducciones: «la argumentación literaria recurre a la explicación biológica y la investigación psicoanalítica se apropia de una figuración de origen literario» (88). Ya ante los textos literarios, el repertorio tópico (desarrollo/subdesarrollo, cambio, revolución, aprendizaje, entre otros) antes historizado, ${ }^{3}$ el trazado de tradiciones según sus figuraciones recurrentes (adolescente romántico, picaresca de izquierda, los que se niegan a crecer si crecer es eso y los soberanos indiferentes) y algunas figuras retóricas (metáfora, quiasmo) son las principales herramientas de costura del cuentito. Piacenza diagnostica coalescencia discursiva con el procedimiento del diagnóstico diferencial, porque observa traducciones que inciden en el "polisistema literario» argentino y conexiones latinoamericanas, pero para mejor señalar la diferencia argentina y la diferencia de los años sesenta. Con todo, esto no termina aquí, porque en los hilvanes está esa política del respeto que llamamos Estado del Arte y que en este libro es no sólo una política académica sino también un efecto de su objeto: cómo se llega a ser lo que se es o a tener esta voz. Lo hace leyendo a los críticos de acá y agradeciendo a Nicolás Rosa.

Habría que preguntarse por qué los investigadores que comienzan por la Didáctica acaban siendo los mejores historiadores, cuando desde fines de los años 80 el cruce entre enseñanza de la literatura e historia de la literatura —otra forma del cuentito- no tiene buena prensa en materiales para la enseñanza y en la investigación didáctica, donde campean los géneros o los corpora didácticos. Piacenza señala este cambio ya en los sesenta, como superación del enciclopedismo (328). Pienso en didactas-historiadores como Analía Gerbaudo, con su Ni Dioses ni bichos y Políticas de exhumación, o en La trama de los textos y Los arrabales de la literatura, de Gustavo Bombini. Tal vez hay que darles razón a los psicoanalistas cuando sostienen que lo que no se dice, se actúa y lo que se olvida, se repite. Piacenza muestra su maestría para historiar cuando articula historia y memoria. La repetición de una estrategia la estatuye como decisión metodológica: ir desde la diacronía de un autor (Miguel Briante o Germán García en los años dos mil) para echar luz sobre la sincronía del corpus sin recurrir a la «generación» o alguna otra artimaña conceptual para trabajar con tiempos discretos. De nuevo, es la potencia centrípeta del cuentito, al que no se le escapa ninguno de los interrogantes medulares de la crítica literaria reciente para historiar: realismo, escrituras del yo, escenas de lectura y apropiación-subjetivación, animalidad, género y sexualidad, cultura y literatura juvenil. Aquella estrategia y este abanico de interrogantes hacen que este libro sea necesario, entre otras razones, porque los corpora literarios utilizados para la Educación Sexual Integral están mayormente armados con los organizadores genéricos y temáticos que este libro interroga (es decir: «la construcción de identidad en los relatos de protagonista femenino y masculino» 0 «La iniciación de la sexualidad», entre otros).

Para finalizar, una observación que es respuesta a la demanda de pensar que el libro hace. Se trata de la denominación de las emociones utilizadas como instrumental crítico. Nunca se sabe en qué giro estamos, pero casi seguro en el giro afectivo o emocional. Si algo nos deja este giro es un refinamiento del léxico con el que podemos dar cuenta de nuestras emociones o reconocer las de los otros. Hay bibliotecas para cada emoción o afecto. Me interesa en particular cómo se trabaja la indignación, una emoción moral inquisitiva que implica juicios o intuiciones sobre lo correcto e incorrecto, por merecido o inmerecido, de un accionar o padecer humano, una emoción que mueve a la venganza y vive en pareja con la vergüenza (indigna la desvergüenza del otro) (cfr. Valdecantos, Nussbaum). En el análisis de Fin de fiesta (Beatriz Guido 1958) como relato de formación 
de protagonista masculino hay dos referencias a la indignación de Adolfo: porque Mariana no tiene el cuerpo que su primo espera ver y por el horror que produce a Adolfo descubrirse igual a ella. El intento de violación de Adolfo a Mariana es la venganza leída en términos de amo-esclavo: Adolfo es el amo esclavizado por conseguir el reconocimiento de los demás amos, para lo cual tiene que poner a Mariana en su lugar. Piacenza anota que, según el narrador, Mariana parece vivir el intento como un castigo merecido y en el capítulo siguiente de la novela se siente feliz. Pero esa anotación queda sin analizar, tal vez porque reparar en esa anotación obligaría a darle protagonismo a Mariana y no a Adolfo. Es posible que la indignación de Adolfo responda más al exceso o desvergüenza de Mariana que a la frustración de sus expectativas; Guido esparce pistas que permiten pensar el protagonismo de Mariana. El análisis de Piacenza comulga con lo que la antropóloga Rita Segato sostiene de los violadores como moralizadores y «hace sistema» con la hipótesis sobre la pornografía de Christian Ferrer que nuestra autora retoma y saluda páginas antes: «la escena pornográfica es el último refugio que le resta al hombre donde manipular hembras a gusto y placer» (282). Atender al léxico emotivo, no obstante, puede depararnos otras lecturas. Quizá Mariana pueda cuestionar que el pudor femenino sea la principal característica del relato de formación de protagonista femenina.

\section{Notas}

1 La noción de «cuentito» recupera tanto la tesis de Ricardo Piglia (1986) sobre el cuento como la de Mauricio Kartun (1995) sobre el cuentito. El primero sostenía que un cuento cuenta siempre dos historias y establecía tipos según cómo las dos historias se enhebran. En este caso: el cuento del crecimiento, formación y desarrollo personal del adolescente cuenta también el cuento desarrollista nacional en los sesenta largos (hasta 1973). El segundo, contraponiendo El Cuentito y la poética teatral como Reserva Imaginaria, aludía a los reclamos de orden narrativo cuya ausencia explicaba, a juicio de muchos espectadores y actores, que la gente ya no iba al teatro. Pero aquí nos interesa el sentido nativo de El Cuentito que reconoce Kartun, para hacerle dos agregados: «El Cuentito es un término convencional que utilizamos habitualmente los dramaturgos [e historiadores] para referirnos al nivel primario de un relato un mapa con el que orientar las, a menudo, caóticas imágenes del creador [y del material documental] ». La potencia del cuentito en este libro hace que no se desborde por la heterogeneidad del corpus: Walsh, Briante, Puig, García, Cortázar, Guido, Piglia, entre otrxs.

2 Los sesenta como objeto son una operación especular de los noventa que comienzan en 1987, así como el kirchnerismo fue medido por propios y ajenos con el alfonsinismo pre-87. El ya clásico Nuestros años sesentas, la «autocrítica generacional» de Oscar Terán (1991), así lo indica: lo que fue sublime devino falaz es la fórmula con la que Omar Acha (2016) resume el relato de formación. El libro de Terán es un balance más en el marco del proceso de reconfiguración de la izquierda democrática iniciado en Punto de Vista. Se comprenden no pocas valoraciones críticas si se lee el libro de Piacenza en este hilo.

3 Lamentamos aquí la ausencia de alusión a las Investigaciones pedagógicas de Saúl Taborda, no sólo porque era un lector avieso de literatura y pensamiento pedagógico alemán sino también por su pretensión de barajar y dar de nuevo con la tradición sarmientina, la misma actitud que Piacenza encuentra en la picaresca de izquierda.

\section{Bibliografía}

Acha, Omar (2016). «La autocrítica de la intelectualidad revolucionaria: Oscar Terán y la historia de las ideas argentinas». Herramienta 59. Web.

Kartun, Mauricio (1995). «El cuentito». Escritos, 1975-2005. Buenos Aires: Colihue, 2006, 50-54. Nussbaum, Martha (2016). Anger and Forgiveness. Nueva York: Oxford UP. 
Piglia, Ricardo (1986). Formas breves. Buenos Aires: Anagrama.

Valdecantos, Antonio (2001). «Emociones responsables». Isegoría 25, 63-90. 